\title{
Lane's Tumor of Maxilla- A Case Report and Review of Literature
}

\author{
Dr. Ekta Rani MD ${ }^{1 *}$, Dr. Sarita Nibhoria MD $^{2}$, Dr. Navjot Kaur, MBBS ${ }^{3}$, Dr. Shilpa Pal, MBBS
}

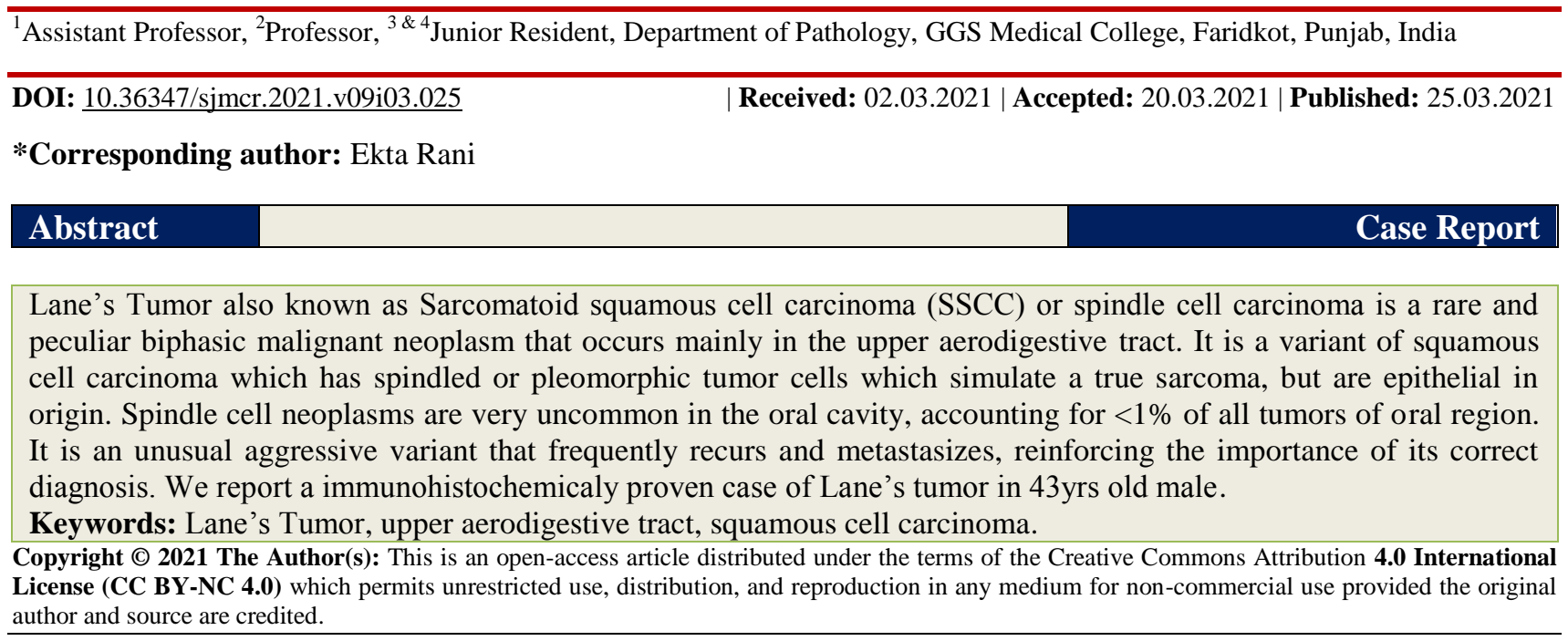

\section{INTRODUCTION}

Lane's Tumor/Sarcomatoid carcinoma/spindle cell carcinoma $(\mathrm{SpCC})$ and polypoid squamous cell carcinoma, is a rare variant of squamous cell carcinoma characterized by dysplastic surface squamous epithelium along with prominent invasive spindle cell element [1]. Patient age ranges from 44 to 88 yrs with a mean age of $65.7 \mathrm{yrs}$ and has more predilection for males [2, 3, 5]. Most common presentation is exophytic and polypoid but endophytic and nodular appearance is also noted [2]. SSCC shows a biphasic histologic appearance with epithelial changes varying from dysplasia to invasive carcinoma and stromal component composed of fusiform or spindle-shaped cells [4]. However, the WHO classification of tumors of the oral cavity and oropharynx has placed this disease entity under malignant epithelial tumors of squamous cell carcinoma (SCC) [5]. Their clinical course is considered aggressive with a high incidence of metastasis [3].

\section{Case Report}

A 43-year-old male patient presented to OPD with a complaint of pain and discomfort in mouth due to growth in the alveolar process of maxilla between molar and canine region since about 15-20 days. Initially the growth was small when he first noticed, then growth rapidly increased in size. Past medical history was insignificant. The patient did not had any habit of smoking and tobacco or alcohol consumption.

General physical examination revealed an otherwise healthy individual with a short and thin built, normal gait, and no history of any fever, headache, or weight loss in the recent past. Lymph nodes were not palpable. Intraorally, an irregular ulcerated grey white to grey brown growth identified in between canine and molar area measuring $1.5 \times 1 \mathrm{~cm}$ on outer surface of alveolar process. CECT Scan of neck and PNS was done which shows - heterogenously enhanching soft tissue density mass lesion of size approx 30x $28 \times 25 \mathrm{~mm}$ involving left side buccal mucosa and adjacent alveolus. Two blocks were received in the department of pathology GGSMCH faridkot. Slides were prepared and hematoxylin \& eosin staining was done. On histopathology Lane's Tumor (Sarcamatoid SSC) was diagnosed which was further confirmed by Immunohistochemistry. 


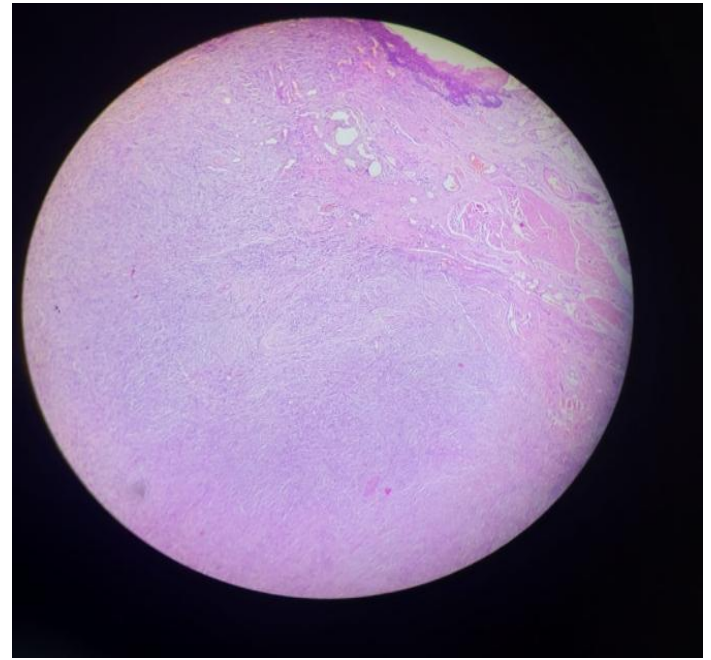

Fig-1: Low power view showing mucosa lined by hyperplastic stratified Squamous lining exhibiting focal ulceration

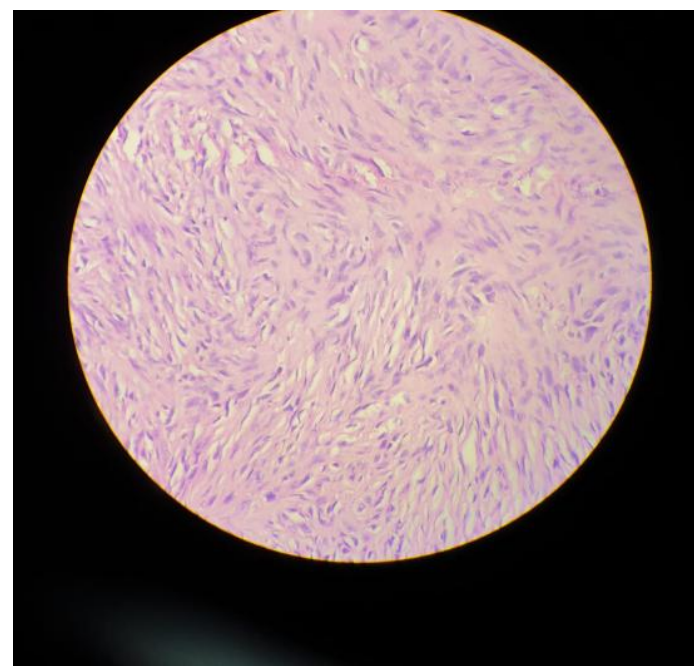

Fig-2: Shows underlying stroma shows an infiltrating malignant tumor composed of spindle shaped cells arranged in intersecting bundles and fascicles

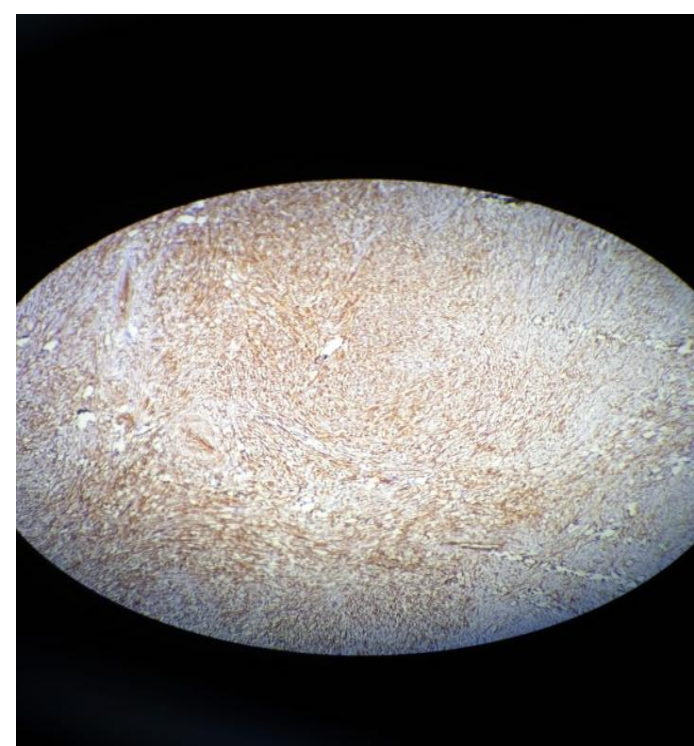

Fig-3: Malignant cells shows cytoplasmic positivity for Cytokeratin

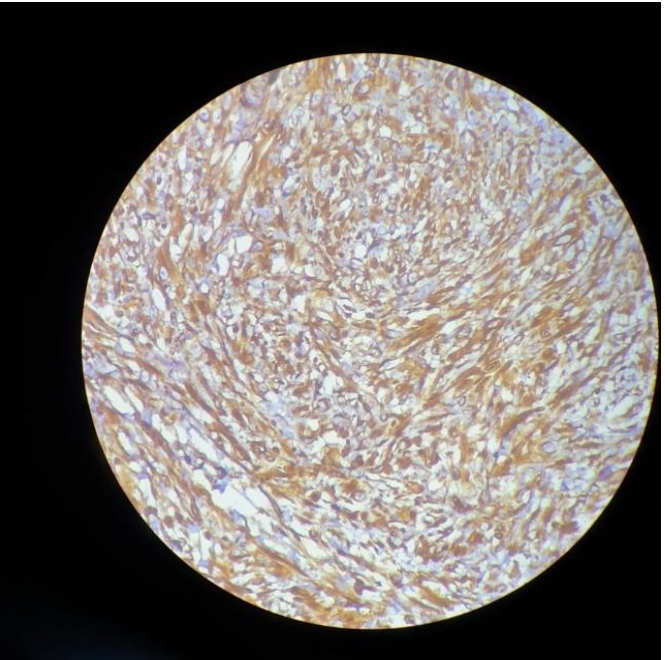

Fig-4: Malignant cells shows cytoplasmic positivity for Vimentin

\section{DISCUSSION}

Lane's Tumor (Sarcamatoid Squamous cell carcinoma) is a rare variant of squamous cell carcinoma characterized by dysplastic surface squamous epithelium along with prominent invasive spindle cell element [1] It is an unusual variant of squamous carcinoma reported to account for $3 \%$ of all SCCs in the head and neck region [4]. It consists of proliferation of both sarcomatoid pleomorphic spindle cells and carcinomatous squamous cells [5]. Many terms are used in the literature to designate SSCC including carcinosarcoma, pseudosarcoma, spindle cell carcinoma, pleomorphic carcinoma, polypoid carcinoma, pseudosarcomatous carcinoma, metaplastic carcinoma and Lane's tumor [5-8]. The initial description of this type of malignancy was reported in 1864 by Virchow, who labeled it as carcinosarcoma [9, 10]. However, Krompecher is credited with proposing the theory that carcinoma cells can undergo sarcomatous transformation [11]. However, the term "spindle cell carcinoma" was first applied by Shervin $e t$ al., [3]. Lane in 1957 proposed the term "pseudocarcinoma" suggesting that it may be a squamous cell carcinoma with an atypical reactive stroma $[2,3]$.

Clinically, Lane's Tumor most commonly presents as a painful swelling or a nonhealing ulcer. The growth configuration is often exophytic polypoid, but sessile, nodular, or endophytic configuration has also been described. The lesion usually has an extensive surface ulceration with friable, fibrinoid necrosis of variable thickness or shaggy exudates [2, 3]. Radiation, trauma, tobacco use, and alcohol consumption seem to play a role as etiological factors [2].

On histopathological examination SC shows a biphasic histologic appearance with surface epithelium showing features of mild dysplasia to invasive carcinoma and an atypical stroma composed of fusiform cells giving a fibrosarcoma-like appearance $[3,12]$. The 
Ekta Rani et al., Sch J Med Case Rep, Mar, 2021; 9(3): 284-287

epithelial component is usually found within the stalk or periphery of the lesion and forms a minor portion of the tumor mass. Sometimes, there is evidence of proliferation and transition of surface basal cells to the spindle cell sarcomatous elements [13].

The sarcomatous component usually makes up the bulk of the tumor and consists of plump spindle cells, which can also be rounded and epithelioid in some regions [13]. A strange feature of this tumor is the relative scarcity of the carcinomatous component [14]. This creates difficulty as the histopathologic diagnosis becomes dependent on the site of the biopsy. If it is taken from the squamous cell component, it can be misdiagnosed as carcinoma, whereas biopsies from spindle cell component tend to be misdiagnosed as sarcoma [2]. Metastatic spread of Lane's Tumor most frequently occurs via the lymphatic route and may consist of pure epithelial or spindle cells or of admixtures of the two histologic patterns [13].

Differential diagnosis includes a number of benign and malignant tumors such as fibromatosis, nodular fasciitis, reactive epithelial proliferations, SCC, fibrosarcoma, malignant fibrous histiocytoma, leiomyosarcoma, rhabdomyosarcoma, malignant peripheral nerve sheath tumor, mesenchymal chondrosarcoma and malignant melanoma $[9,10,15$, 16].

The morphology of the spindle cells in SSCC cannot be just predicted by routine light microscopy but requires the use of immunohistochemistry (IHC). Cytokeratin (CK) is considered the most reliable epithelial marker but epithelial membrane antigen (EMA) and carcinoembryonic antigen (CEA) can also be useful [12]. Vishwanathan et al., in their review of 103 cases of SC observed that CK and EMA were most useful and positive in $61.3 \%$ of cases [4]. Thompson et al. in their review of 187 cases of laryngeal SC reported that $100 \%$ of cases tested expressed vimentin, with $33 \%$ demonstrating reactivity with smooth muscle actin, $15 \%$ with muscle specific actin, $5 \%$ with $S-100$ protein, and $2 \%$ each with desmin-D33 and desmin-DR11 [8]. IHC of the incisional biopsy in our case showed a strong cytoplasmic positivity for vimentin and focal positivity for pancytokeratin.

Management of Lane's Tumor is as tricky and controversial as its diagnosis. Wide surgical excision, with or without radical neck dissection, seems to be the most preferred and successful therapeutic modality. Radiotherapy, although considered to be ineffective by most authors, is an acceptable alternative for inoperable patients as well as for those in which the surgical margins are positive or in patients with nodal metastasis $[2,13]$.
Prognosis of Lane's Tumor is dependent on location, size, and depth of invasion of tumor, stage of disease, and the presence of any keratin staining in the spindle cells $[2,14]$. Lane's tumor of the oral cavity and oropharynx is potentially aggressive and tends to recur and metastasize easily [2].

A clear understanding of clinicopathologic characteristics and immunohistochemistry is indispensable for diagnosis and management of Lane's Tumor. Treatment should aim at controlling local and distant recurrence. Patients with deeply invasive tumors tend to have a poor prognosis, whereas those with earlystage tumors have excellent prognosis.

\section{CONCLUSiON}

Lane's Tumor (Sarcomatoid carcinoma) of the oral cavity is rare in occurrence and aggressive in nature. Although histopathology is gold standard for diagnosis but immunohistochemistry is mandatory for confirmation.

\section{REFERENCES}

1. Neville BW, Damm DD, Allen CM, Bouquot JE. Oral and Maxillofacial Pathology, Saunders, Philadelphia, 3rd edition edition, 2009.

2. Kwon GY, Choi YJ, Song MS, Yun KI. Sarcomatoid carcinoma of the mandible: report of a case. Journal of the Korean Association of Oral and Maxillofacial Surgeons. 2010;36(3):228-30.

3. Prakash N, Kumar H, Sharada P, Pradeep GL. Spindle cell carcinoma of the oral cavity: a case report of a rare entity and review of literature. World Journal of Dentistry, 2010;1(1), 55-58.

4. Viswanathan S, Rahman K, Pallavi S, Sachin J, Patil A, Chaturvedi P, D'Cruz A, Agarwal J, Kane SV. Sarcomatoid (spindle cell) carcinoma of the head and neck mucosal region: a clinicopathologic review of 103 cases from a tertiary referral cancer centre. Head and neck pathology. 2010 Dec 1;4(4):265-75.

5. Parikh N, Desai N. Spindle cell carcinoma of the oral cavity: A case report of a rare entity and review of literature. J Acad Adv Dent Res. 2011;2:31-6.

6. Köseoğlu D, Sertçelik A, Ayva Y. A rare variant of squamous cell carcinoma of the tongue; spindle cell carcinoma. Ankara Üniv Fak Mecm. 2005;58:11-4.

7. Thompson LD, Wieneke JA, Miettinen M, Heffner DK. Spindle cell (sarcomatoid) carcinomas of the larynx: A clinicopathologic study of 187 cases. Am J Surg Pathol. 2002;26:153-70.

8. Verco S, Chambers I, Hall G. Maxillary sarcomatoid carcinoma. Oral Surg Oral Med Oral Pathol Oral Radiol. 2012;114:e31-5.

9. Sarma A, Das R, Sharma JD, Kataki AC. Spindle cell carcinoma of the head and neck: A 
clinicopathological and immunohistochemical study of 40 cases. J Cancer Ther. 2012;3:1055-9.

10. Kwon GY, Choi YJ, Song MS, Yun KI. Sarcomatoid carcinoma of the mandible: Report of a case. J Korean Assoc Oral Maxillofac Surg. 2010;36:228-30.

11. Shirsat PM, Desai RS, Bansal S, Deshpande M. Sarcomatoid carcinoma of maxillary sinus: Report of an unusual case and review of literature. Int $\mathbf{J}$ Oral Maxillofac Pathol. 2013;4:80-4.

12. Batsakis JG, Rice DH, Howard DR. The pathology of head and neck tumors: spindle cell lesions (sarcomatoid carcinomas, nodular fasciitis and fibrosarcoma) of the aerodigestive tracts, part 14, Head \& Neck Surgery, 1982;4(6), 499-513.
13. Rizzardi C, Frezzini C, Maglione M, Tirelli G, Melato M. A look at the biology of spindle cell squamous carcinoma of the oral cavity: report of a case. Journal of oral and maxillofacial surgery. 2003 Feb 1;61(2):264-8.

14. Minami SB, Shinden S, Yamashita T. Spindle cell carcinoma of the palatine tonsil: report of a diagnostic pitfall and literature review. American journal of otolaryngology. 2008 Mar 1;29(2):123-5.

15. Olsen KD, Lewis JE, Suman VJ. Spindle cell carcinoma of the larynx and hypopharynx. Otolaryngology-Head and Neck Surgery. 1997 Jan;116(1):47-52.

16. Thompson LD. Squamous cell carcinoma variants of the head and neck. Mini-Symposium: Head and neck Pathology. Curr Diagn Pathol. 2003;9:384-96. 